\title{
A comparison of open versus percutaneous cervical transfacet fixation
}

\author{
Adeel Husain, MD, ${ }^{1}$ Yusuf T. Akpolat, MD, ${ }^{1}$ Daniel K. Palmer, BS, ${ }^{2}$ David Rios, BS, ${ }^{2}$ \\ Kevin R. Criswell, MA, ${ }^{3}$ and Wayne K. Cheng, MD' \\ 1Department of Orthopaedic Surgery and ${ }^{3}$ School of Behavioral Health, Loma Linda University; and 'Loma Linda University \\ School of Medicine, Loma Linda, California
}

\begin{abstract}
OBJECTIVE The aim of this study is to describe a technique for percutaneous cervical transfacet screw placement and compare this technique to the open technique with regard to the accuracy of facet capture and the potential of placing neurovascular structures at risk.
\end{abstract}

\begin{abstract}
METHODS Eight cadaveric cervical spines were harvested. One side of each spine was assigned to the percutaneous group, and the other side to the open group. The spines were instrumented from C-3 to T-1 ( 80 screws). The distance to the spinal canal, foramen transversarium, and neural foramen were measured to determine the likelihood of placing neurovascular structures at risk. The percentage of the facet joint captured and the angle of screw trajectory compared with the ideal trajectory were used to determine the accuracy.
\end{abstract}

RESULTS There were, in total, 11 misplacements of screws: 2 screws using the open technique and 9 screws using the percutaneous technique $(p=0.006)$. From a neurovascular point of view, 3 percutaneous screws violated the foramen transversarium. Two of these percutaneous screws violated the neural foramen. No neurovascular foramina were violated using the open technique. The open technique resulted in a significantly greater distance from the screw to the spinal canal $(p<0.001)$. The distance from the screw to the foramen transversarium $(p=0.015)$, as well as the distance from the screw to the neural foramen $(p=0.012)$, did not demonstrate statistical difference when using either technique. As for the accuracy of facet capture, 8 screws exhibited less than $15 \%$ purchase of the facet joint. Six of these screws were placed using the percutaneous technique, and 2 screws were placed using the open technique.

CONCLUSIONS There is a higher incidence of screw misplacement using the percutaneous transfacet in comparison to the open transfacet technique. The accuracies of facet capture using the 2 techniques were not statistically different. Surgeons will need to understand the potential risk of using the percutaneous technique as an alternative to open transfacet fixation.

http://thejns.org/doi/abs/10.3171/2016.2.SPINE151334

KEY WORDS percutaneous transfacet fixation; transarticular; accuracy; open transfacet fixation; cervical; technical approach; safety; violation

$\mathrm{P}$ OSTERIOR cervical fusion has gained wide acceptance for the treatment of the unstable cervical spine caused by trauma, neoplasm, degenerative conditions, and other cervical pathologies. ${ }^{2,6}$ Several fixation techniques are currently in use, such as those that use interspinous wiring, hook plates, and lateral mass screws and rods, with lateral mass constructs being the most common fixative for posterior subaxial cervical spinal fusions. ${ }^{1}$ The most stable techniques use rigid 3-column fixation; however, these techniques are very technically difficult. Transfacet fixation shows statistically similar biomechanical stability with a theoretically better safety profile. Posterior cervical fixation techniques are evolving based on increased biomechanical stability, increasing technical ease of new procedures, and decreased morbidity with less invasive procedures. The true indication for transfacet instrumentation is not clear. Potential usage may include backing up anterior multilevel constructs, as well as "bailing out" failed posterior instrumentation techniques during surgery (Fig. 1).

Transfacet screws have a better safety profile compared with lateral mass and cervical pedicle screws. ${ }^{8}$ Anatomical descriptions suggest that transfacet screws are superior to lateral mass screws in avoiding damage to the vital structures. ${ }^{7,11,13}$ Liu et al. ${ }^{8}$ compared the potential incidence of nerve root (ventral and dorsal rami) injury and concluded that the potential risk of nerve root invasion is lower with Klekamp transarticular screws than with Roy-Camille 


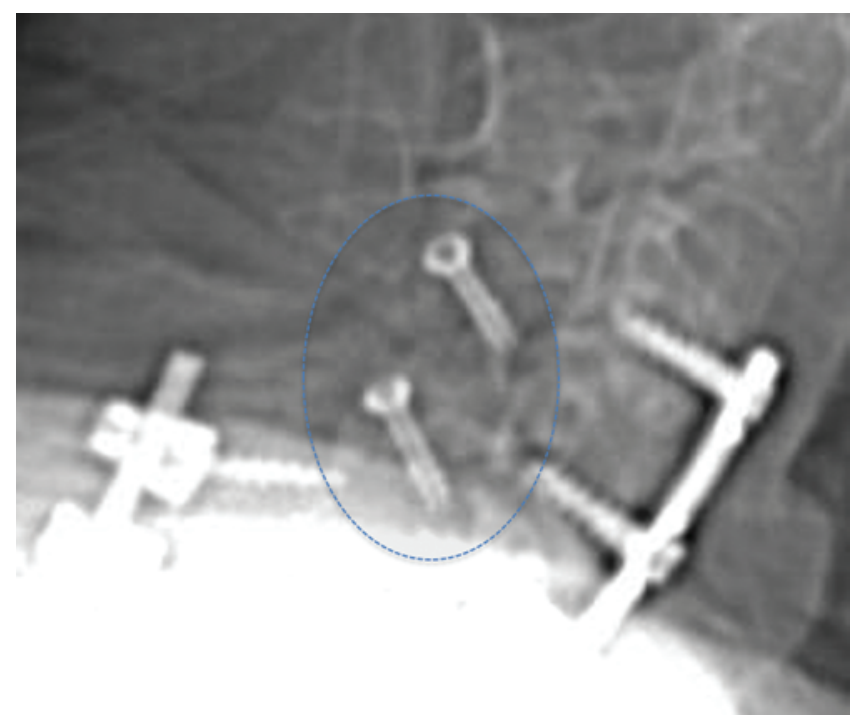

FIG. 1. Radiograph showing transfacet screws (dotted circle) augmenting the anterior cervical fusion. Figure is available in color online only.

lateral mass screws. However, it has been noted that the placement of transfacet screws is technically challenging. ${ }^{6}$ The screw is surrounded by important anatomical structures: nerve roots lie anteriorly and inferiorly, the spinal cord lies medially, and the vertebral artery lies anteriorly. The steep caudal and lateral angle required for fixation may also add to the risks of this procedure.

Percutaneous posterior spinal stabilization is becoming more popular for the treatment of common spinal pathologies. ${ }^{12}$ During spinal stabilization procedures, it is desirable to minimize soft-tissue trauma and retain the normal anatomy of the facets. Minimally invasive approaches to spinal stabilization tend to reduce the exposure area and its associated morbidities such as blood loss, perioperative pain, and potential for infection. ${ }^{3}$ The technique of facet fixation provides an attractive option in this regard.

Takayasu et al. and others ${ }^{5,13}$ have described transfacet screws in the cervical spine as an alternative technique to achieving posterior spinal stability. We have been unable to find any technique descriptions or safety reports regarding percutaneous cervical transfacet screw placement in the literature. Here, we describe a technique for percutaneous cervical transfacet screw placement and compare this technique to the described Dalcanto open technique in regards to the violation of neurovascular structures and the accuracy of screw placement. ${ }^{2}$

\section{Methods}

Eight cadaveric cervical spines with the head attached were harvested from 4 male and 4 female embalmed cadavers. The mean age of the cadavers was 61 years. Cadavers with previous cervical spine surgery were excluded. Anteroposterior and lateral radiographs were taken of each cervical spine to ensure that there was no destructive process of bone. The cadaveric heads and cervical spines were then placed prone on a Jackson table with a padded horseshoe holder to stabilize the head, as is done in sur-

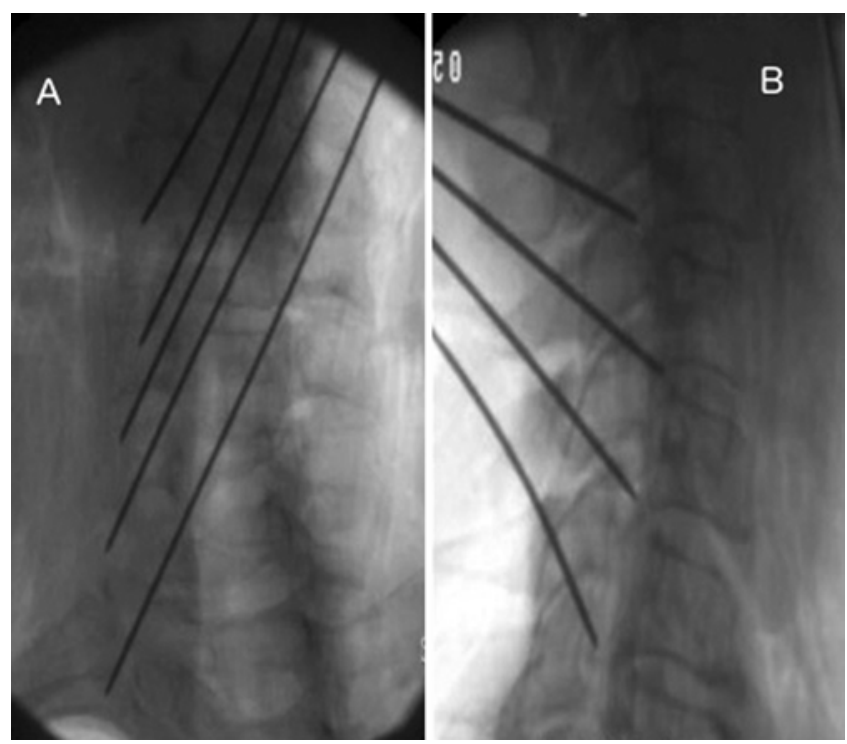

FIG. 2. Fluoroscopic images of the initial K-wires in the anteroposterior (A) and lateral planes (B).

gery of the posterior spine. Biplanar fluoroscopy was set up to image both the anteroposterior and lateral views of the spine. One side of each spine was assigned to the percutaneous group, and the other side to the open group.

The percutaneous technique was performed first for all levels. This was then followed by the open technique on the contralateral side. Stab incisions were made at the midline, beginning at the occipital protuberance down to the level of $\mathrm{C}-5$ over the spinous processes. Then K-wires were drilled through the muscle bulk of the posterior neck in order to attain an appropriate starting point on the lateral mass for the transfacet screws (Fig. 2). Dalcanto's starting point was defined as $1 \mathrm{~mm}$ medial and $1 \mathrm{~mm}$ caudal to the midpoint of the lateral mass. This point was confirmed on anteroposterior and lateral fluoroscopy prior to the insertion of the K-wire into the lateral mass. The wires were drilled with a trajectory $40^{\circ}$ caudally and $20^{\circ}$ lateral to the cervical spine axis. ${ }^{6}$ The target point, at the juncture between the transverse process and the facet joint, was the safest point for avoiding the vertebral artery and the nerve roots. Once the K-wires were placed, 2 fluoroscopic views were taken to ensure accurate placement. Subsequently, a 4.0-mm-diameter and 16-mm-long self-tapping cannulated screw (Synthes) was drilled through the facet joint, capturing the inferior and superior facets of the adjacent cervical vertebrae (Fig. 3). Once the percutaneous technique was performed to fix the C3-4, C4-5, C5-6, C6-7, and C7-T1 facet joints, the open technique was then performed on the other side.

The open side was cut sharply with a scalpel, connecting the previous stab incisions from the occipital protuberance to the level of $\mathrm{C}-5$. The posterior cervical musculature was incised from the midline incision. Care was taken to dissect down to bone, exposing the lamina and medial aspect of the lateral mass, as is done in the normal open surgical approach to the posterior cervical spine. The Dalcanto starting point for the K-wire was identified under 

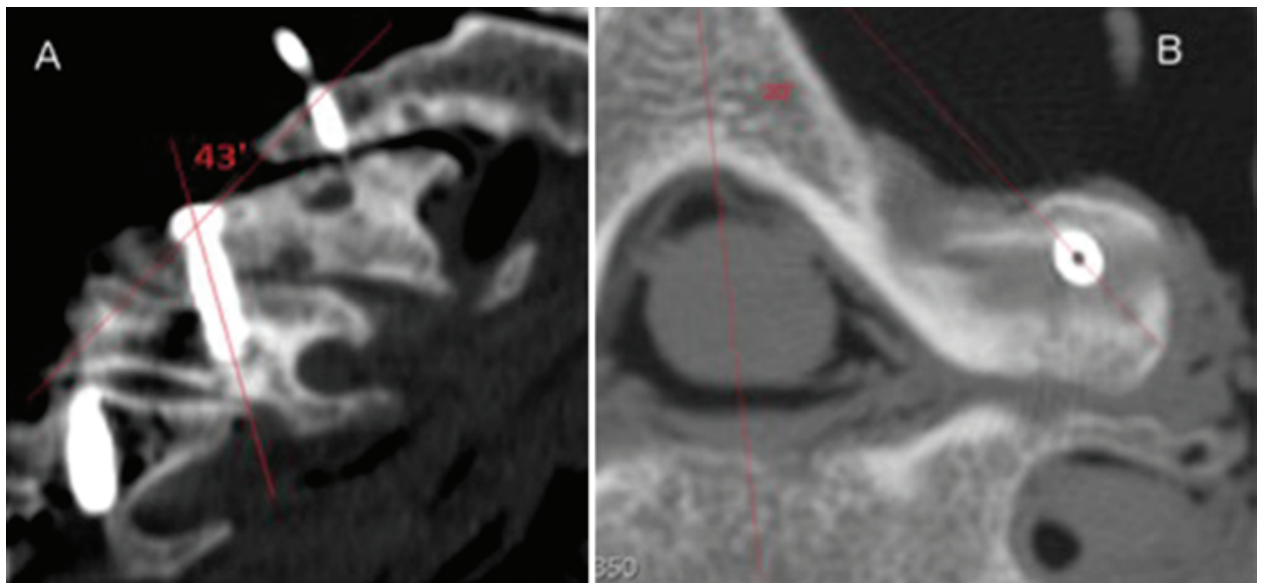

FIG. 3. CT images showing $43^{\circ}$ caudal (A) and $20^{\circ}$ lateral trajectory (B) of the screws. Figure is available in color online only.

direct visualization. K-wires were then drilled across the facet joints along the same trajectory, as was done with the percutaneous technique. Anteroposterior and lateral fluoroscopic images were obtained for each level again, as was done with the percutaneous technique, to ensure accurate placement of the wires. Self-tapping cannulated screws (Synthes) that were $4.0 \mathrm{~mm}$ in diameter and $16 \mathrm{~mm}$ in length were then placed across the C3-4, C4-5, C5-6, C6-7, and C7-T1 facet joints.

The final anteroposterior and lateral radiographs (Fig. 4) and fine-cut (0.625-mm-thick) CT scans (Light Speed 16 Multi Detector; GE Medical System) with reconstructions (Fig. 5) were then taken of each cadaveric spine. These CT images, as well as cadaveric dissection, were then used to determine screw position. The data from both the open and percutaneous approaches were used to assess violation of the neurovascular structures and the accuracy of screw placement. Predictive Analytics Software (version 18.0; PASW) was used to run repeated-measures multivariate ANOVA and subsequent univariate analyses.

The definition of the misplacement was thus defined: 1) violation of neurovascular landmarks, as defined as a) violation of the neural foramen, b) violation of the foramen

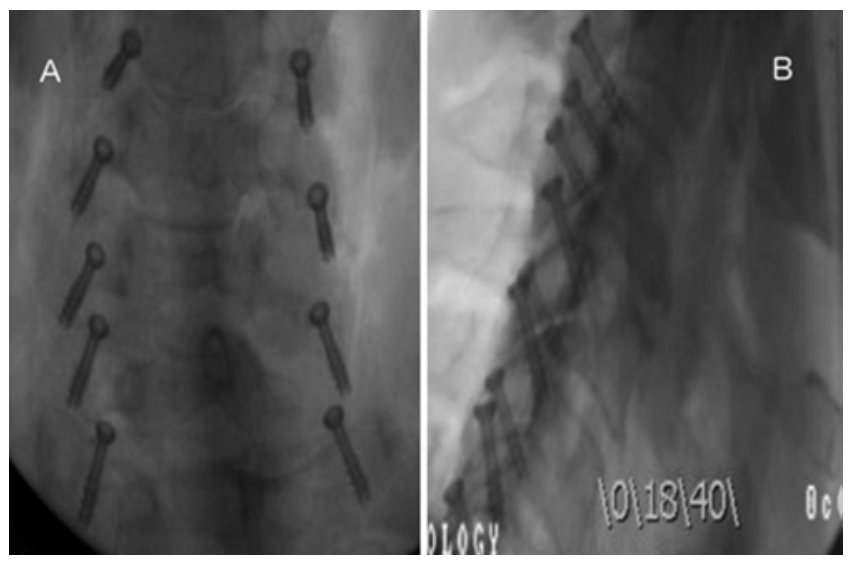

FIG. 4. Fluoroscopic images of the placed screws in the anteroposterior (A) and lateral planes (B). transversarium, and c) violation of the spinal canal; and 2) inadequate facet fixation, as defined as facet joint surface capture less than $15 \%$.

The violation of the neurovascular structures was quantified by 2 means: 1) the number of violations of the spinal canal, foramen transversarium, and neural foramen that could potentiate vertebral artery or nerve root violation; and 2) the proximity in millimeters of the screws to those previously mentioned structures. Violations of the neurovascular structures were counted on the CT scans and confirmed by cadaveric dissection. Proximity was measured in millimeters on CT; however, this could not be quantified on the cadavers.

The accuracy of facet capture was quantified by 2 means: 1) the angle of the screw as it crossed the facet articulation; and 2) the percentage of facet captured. The ideal angle trajectory was defined as the screw crossing
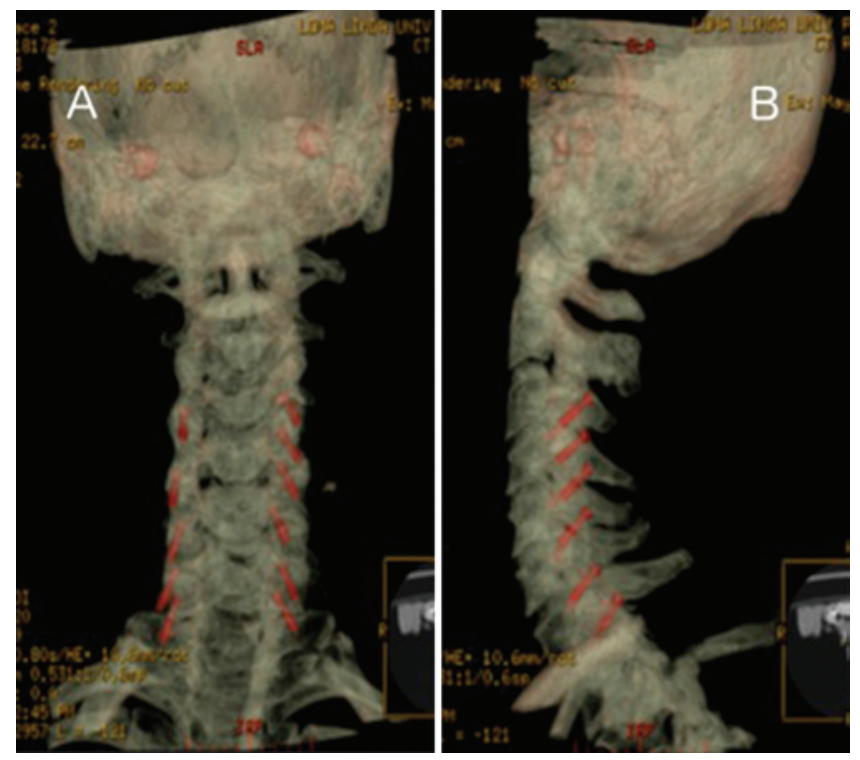

FIG. 5. Three-dimensional CT reconstructions of the cervical spines with the placed screws in the anteroposterior (A) and lateral views (B). Figure is available in color online only. 


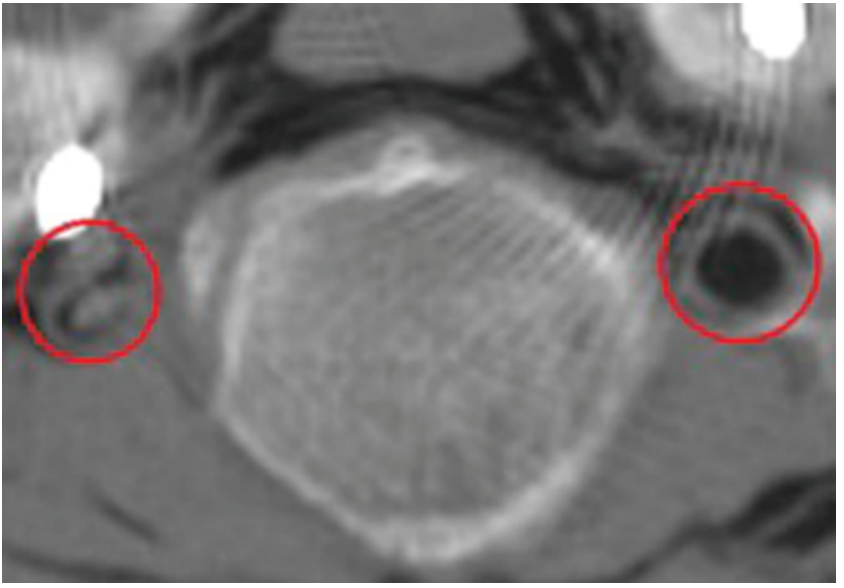

FIG. 6. Breach (circle) of the foramen transversarium with the percutaneous technique. Figure is available in color online only.

the facet perpendicularly $-20^{\circ}$ in the axial plane and $40^{\circ}$ in the sagittal plane-in relation the cervical spine axis. ${ }^{14}$ Ideal facet capture was at the midpoint-midpoint position on the axial and sagittal images at facet articulation. The amount of facet captured at the joint was quantified as the percentage of the facet captured. This was calculated by taking a ratio of the distance from the lateral border of the facet to the facet length on the axial view, and the superior border of the facet to the center of the screw to the entire length of facet articulation on the sagittal view. The average of the axial and sagittal ratios provided a value for the overall percentage of facet captured.

\section{Data Analysis}

The chi-square test was used for comparison of the malposition rate. One-way repeated-measures multivariate ANOVA was run to determine if a significant multivariate within-subjects effect of the surgical approach existed for any of the following 5 assessments: the closest distance from the screw to 1) the spinal canal, 2) neural foramen on the axial image, and 3) foramen transversarium, 4) the ratio of screw purchase, and 5) the angle of the screw at the facet joint. If a significant repeated-measures effect of surgical technique were found, univariate tests of withinsubjects effects would be interpreted to determine how the open and percutaneous techniques differ depending on the observed outcome measure. A Bonferroni correction for 5 comparisons was implemented to control for Type I errors: the significance level was set to $\alpha=0.01(\alpha=[0.05 / 5]$ $=0.01)$ on the 2-tailed test.

\section{Results}

Eighty cervical transfacet screws were placed: 40 were placed using each technique. There were a total of 11 misplacements of the screws: 2 screws using the open technique and 9 screws using the percutaneous technique ( $\mathrm{p}$ $=0.006)$.

Overall, 3 screws violated the neurovascular landmarks and 8 screws exhibited poor accuracy of facet capture. No screws penetrated into the spinal canal. Three percuta-

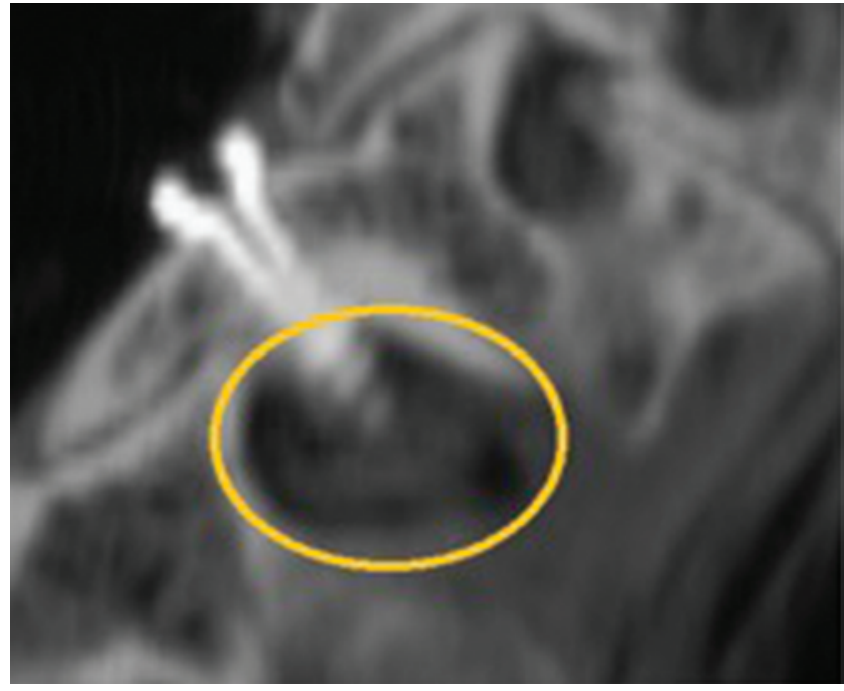

FIG. 7. True breach (circle) of the neural foramen with the percutaneous technique. Figure is available in color online only.

neous screws violated the foramen transversarium (Fig. 6). Two of those same percutaneous screws violated the neural foramen (Fig. 7). No neurovascular structures were violated by the screws placed using the open technique. Ninety percent of all the screws had ideal facet capture. Eight screws (10\%) exhibited poor accuracy, which was described as less than 15\% purchase of the facet joint, missed facet, or facet fracture. Six of these screws were placed using the percutaneous technique, and 2 screws were placed using the open technique (Table 1).

The results of 1-way repeated-measures multivariate ANOVA demonstrated a significant multivariate withinsubjects effect of surgical technique $(F(5,33)=4.44 ; \mathrm{p}=$ $0.003)$. Therefore, univariate tests of the within-subjects effect of surgical technique were interpreted. Using a significance level of $\alpha=0.01,1$ of the 5 tests was significant.

The open technique resulted in a significantly greater distance from the screw to the spinal canal ( $p<0.001$ ) than the percutaneous technique. The surgical techniques did not statistically differ in terms of the distance from the

TABLE 1. Absolute number of complications in each surgical technique according to safety and accuracy

\begin{tabular}{lcc}
\hline \multicolumn{1}{c}{ Variable } & $\begin{array}{c}\text { Open Technique } \\
(n=40)\end{array}$ & $\begin{array}{c}\text { Percutaneous } \\
\text { Technique }(n=40)\end{array}$ \\
\hline Safety & & 0 \\
\hline$\quad$ Violation of spinal canal & 0 & 3 \\
\hline $\begin{array}{l}\text { Violation of foramen trans- } \\
\text { versarium }\end{array}$ & 0 & $2^{*}$ \\
\hline$\quad$ Violation of neural foramen & 0 & \\
\hline Accuracy & 2 & 6 \\
\hline$\quad<15 \%$ purchase of facet joint & 2 & 9 \\
\hline Total complications $\dagger$ & \\
\hline$*$ The same screws violated the vertebral foramen. & \\
$\dagger p=0.006$. &
\end{tabular}


TABLE 2. Measurements of the distance from the screw to the listed structure by each surgical technique

\begin{tabular}{lccr}
\hline \multicolumn{1}{c}{ Variable } & $\begin{array}{c}\text { Percutaneous } \\
\text { Open Surgical } \\
\text { Technique (SD)* }\end{array}$ & $\begin{array}{c}\text { Surgical } \\
\text { Technique (SD) }\end{array}$ & $\begin{array}{c}p \\
\text { Value }\end{array}$ \\
\hline Spinal canal & $8.46(3.33)$ & $6.41(2.98)$ & $<0.001$ \\
\hline Foramen transversarium & $6.06(4.06)$ & $5.15(3.90)$ & 0.015 \\
\hline Neural foramen & $3.85(1.62)$ & $2.76(2.34)$ & 0.012 \\
\hline
\end{tabular}

* Values are given in millimeters.

screw to the foramen transversarium $(p=0.015)$, distance from the screw to the neural foramen $(\mathrm{p}=0.012)$ (Table $2)$, screw purchase ratio $(\mathrm{p}=0.018)$, and angle $(\mathrm{p}=0.025)$ (Table 3).

\section{Discussion}

Posterior transfacet screws have been described as a minimally invasive means of instrumenting the posterior cervical spine. The benefit of placing these screws percutaneously through stab incisions provides the patient a reduced risk of postoperative morbidity.

Several studies to date demonstrate cervical transfacet fixation to be a biomechanically and clinically viable option for posterior cervical fusion. Six biomechanical studies found cervical transfacet screws to exhibit comparable, if not higher, pullout strength than lateral mass screws. ${ }^{2,4,6,9-11}$ This may be explained by more purchase through the cortical and subchondral bone through the dorsal cortex of the lateral mass, the cortical bone of the inferior and superior articular processes, and the ventral surface of the facet. Four cortices are fixed with transfacet screws in comparison with 2 cortices with lateral mass screws. ${ }^{13}$ Miyanji et al. ${ }^{11}$ showed in a biomechanical study with 16 cadaveric cervical spines that transfacet screws (with and without rods) were found to have statistically similar biomechanical stability to lateral mass screw and rod constructs. Dalcanto et al. ${ }^{2}$ showed no significant differences between facet screws and lateral mass plates in 2-level instrumentations of the cervical spine in regards to the range of motion and stiffness in flexion, extension, lateral bending, and torsion. These biomechanical studies compare transfacet fixation to the present posterior cervical fixation techniques and give mechanical evidence of the stability of this construct for posterior spine fixation.

\section{Violation of the Spinal Canal}

The average distance from the 16-mm-long screw to the spinal canal was $2 \mathrm{~mm}$ greater $(\mathrm{p}<0.001)$ in the open group compared with the percutaneous group. However, the clinical relevance of this difference is limited, as there were no violations of the spinal canal in either group and the shortest average distance was $6.4 \mathrm{~mm}$, or one-third of the length of the screws used.

\section{Violation of the Foramen Transversarium}

The foramen transversarium was violated with 3 screws, all of which were placed using the percutaneous
TABLE 3. Measurements of purchase of the screw and trajectory (angle) by each surgical technique

\begin{tabular}{cccc}
\hline Variable & $\begin{array}{c}\text { Open Surgical } \\
\text { Technique (SD) }\end{array}$ & $\begin{array}{c}\text { Percutaneous } \\
\text { Surgical } \\
\text { Technique (SD) }\end{array}$ & p Value \\
\hline Purchase ratio & $0.42(0.14)$ & $0.50(0.19)$ & 0.018 \\
\hline Angle, degrees & $24.01(7.05)$ & $21.38(11.09)$ & 0.025 \\
\hline
\end{tabular}

technique. The average distance from the screw to the foramen transversarium was $5.2 \mathrm{~mm}$ in the percutaneous group and $6.0 \mathrm{~mm}$ in the open group $(\mathrm{p}=0.015)$. Two of these absolute violations occurred in the same cadaveric spine, which was the first spine operated on in the experiment. This difference in distances was not significant and shows a weighted importance compared with the absolute number of violations.

\section{Violation of the Neural Foramen}

The average distances between the screw and the neural foramen did not significantly differ between groups ( $\mathrm{p}$ $=0.012$ ). However, the neural foramen was violated by 2 screws, both of which were placed using the percutaneous technique. One of these screws was the same screw that violated the foramen transversarium in the first spine operated on in this experiment. The breach of the second screw was a true breach through the unilateral cortex. The open technique of transfacet fixation was safe and yielded no violations during this experiment.

\section{Accuracy of Facet Capture}

The accuracies of facet capture using the 2 techniques were not statistically different. Ninety percent of all the screws had ideal facet capture. Eight screws (10\%) had less than $15 \%$ purchase of the facet joint, 6 of which were placed using the percutaneous technique and 6 of which occurred at the C7-T1 facet. One screw each from the percutaneous and open groups missed the facet completely, both of which occurred on at the level of C7-T1. This high percentage of technical error at C7-T1 was likely due to the extreme lateral angle necessary for facet capture and the difficulty of radiographic confirmation at the starting point due to distortion from the shoulder girdle obscuring the radiograph. There was 1 case of facet fracture in the percutaneous group and no obvious cases of facet distraction.

The learning curve could be an important issue in this study. Two of 3 screws in the first cadaveric spine violated an anatomical landmark that would place neurovascular structures at risk. Those screws were placed using the percutaneous technique. If the first specimen was taken out from the experiment, then the chance of placing neurovascular structures at risk would not be significant when comparing the open and percutaneous technique $(\mathrm{p}=0.074)$.

There were multiple limitations to this study. First, the percutaneous technique used to place transfacet screws was novel. The technique had not been described, and both surgeons involved in the case had never done one. This was reflected by the fact that 2 misplacements oc- 
curred in the first specimen, which likely depicts the learning curve for this technique. Second, the cadavers were placed in a padded horseshoe holder. It is possible that more stability could be achieved with the Mayfield headholder. However, the stability of the head did not appear to be a problem during the experiment. In addition, based on the retrospective CT analysis, violation would have been prevented with the use of 14-mm-long screws instead of the $16-\mathrm{mm}$-long screws. We only had 16-mm-long screws available during this experiment due to budget constraints. Finally, both surgeons who placed the screws were righthanded. Even though the surgeon could choose to be on either side of the cadavers, handedness could have affected the results of the study.

Based on our study, we recommend the percutaneous posterior cervical technique using 4.0-mm-diameter cannulated screws with a 14-mm maximum length. From a technique point of view, for more cephalad cervical levels it is important to start at or just below the occipital protuberance for the stab incisions. A midline stab incision that bears slightly toward the contralateral side is beneficial for making the lateral angle necessary for accurate capture of the facet. The starting point for the transfacet screw should be near the center of the inferior facet with a trajectory of approximately $40^{\circ}$ caudal and lateral to the floor. It is not recommended to fuse the $\mathrm{C} 7-\mathrm{T} 1$ level with percutaneous techniques.

\section{Conclusions}

There is a higher incidence of misplacement using the percutaneous transfacet technique in comparison with the open transfacet technique. The distances from the screw to the neurovascular structures were statistically similar between both techniques. The accuracies of facet capture using the 2 techniques were not statistically different. Surgeons will need to understand the potential risk of using percutaneous techniques as alternatives to open transfacet fixation.

\section{References}

1. Barrey C, Mertens P, Rumelhart C, Cotton F, Jund J, Perrin G: Biomechanical evaluation of cervical lateral mass fixation: a comparison of the Roy-Camille and Magerl screw techniques. J Neurosurg 100 (3 Suppl Spine):268-276, 2004

2. DalCanto RA, Lieberman I, Inceoglu S, Kayanja M, Ferrara L: Biomechanical comparison of transarticular facet screws to lateral mass plates in two-level instrumentations of the cervical spine. Spine (Phila Pa 1976) 30:897-902, 2005

3. Harris EB, Massey P, Lawrence J, Rihn J, Vaccaro A, Anderson DG: Percutaneous techniques for minimally invasive posterior lumbar fusion. Neurosurg Focus 25(2):E12, 2008

4. Horn EM, Reyes PM, Baek S, Senoglu M, Theodore N, Sonntag VK, et al: Biomechanics of C-7 transfacet screw fixation. J Neurosurg Spine 11:338-343, 2009
5. Horn EM, Theodore N, Crawford NR, Bambakidis NC, Sonntag VK: Transfacet screw placement for posterior fixation of C-7. J Neurosurg Spine 9:200-206, 2008

6. Klekamp JW, Ugbo JL, Heller JG, Hutton WC: Cervical transfacet versus lateral mass screws: a biomechanical comparison. J Spinal Disord 13:515-518, 2000

7. Liu G, Xu R, Ma W, Sun S, Feng J: Anatomical considerations for the placement of cervical transarticular screws. J Neurosurg Spine 14:114-121, 2011

8. Liu GY, Xu RM, Ma WH, Ruan YP, Sun SH, Huang L: Anatomic comparison of transarticular screws with lateral mass screws in cervical vertebrae. Chin J Traumatol 10:67-71, 2007

9. Liu GY, Xu RM, Ma WH, Sun SH, Huang L, Ying JW, et al: Biomechanical comparison of cervical transfacet pedicle screws versus pedicle screws. Chin Med J (Engl) 121:13901393,2008

10. Mahar A, Kim C, Oka R, Odell T, Perry A, Mirkovic S, et al: Biomechanical comparison of a novel percutaneous transfacet device and a traditional posterior system for single level fusion. J Spinal Disord Tech 19:591-594, 2006

11. Miyanji F, Mahar A, Oka R, Newton P: Biomechanical differences between transfacet and lateral mass screw-rod constructs for multilevel posterior cervical spine stabilization. Spine (Phila Pa 1976) 33:E865-E869, 2008

12. Su BW, Cha TD, Kim PD, Lee J, April EW, Weidenbaum M, et al: An anatomic and radiographic study of lumbar facets relevant to percutaneous transfacet fixation. Spine (Phila Pa 1976) 34:E384-E390, 2009

13. Takayasu M, Hara M, Yamauchi K, Yoshida M, Yoshida J: Transarticular screw fixation in the middle and lower cervical spine. Technical note. J Neurosurg 99 (1 Suppl):132-136, 2003

14. Zhao L, Xu R, Liu J, Konrad J, Ma W, Jiang W, et al: Comparison of two techniques for transarticular screw implantation in the subaxial cervical spine. J Spinal Disord Tech 24:126-131, 2011

\section{Disclosures}

The authors report no conflict of interest concerning the materials or methods used in this study or the findings specified in this paper.

\section{Author Contributions}

Conception and design: Cheng, Husain. Acquisition of data: Cheng, Husain, Akpolat, Palmer, Rios. Analysis and interpretation of data: Cheng, Akpolat, Criswell. Drafting the article: all authors. Critically revising the article: Cheng, Husain, Akpolat, Palmer, Rios. Reviewed submitted version of manuscript: all authors. Approved the final version of the manuscript on behalf of all authors: Cheng. Statistical analysis: all authors. Administrative/technical/material support: Cheng. Study supervision: Cheng.

\section{Correspondence}

Wayne K. Cheng, Department of Orthopaedic Surgery, Loma Linda University, 900 E Washington St., Ste. \#301B, Colton, CA 92324.email: md4spine@yahoo.com. 